Check for updates

Cite this: RSC Adv., 2020, 10, 37766

\title{
Correction: Influence of $\mathrm{Cu}$ doping on the visible- light-induced photocatalytic activity of $\mathrm{InVO}_{4}$
}

\author{
Natda Wetchakun, (D) *a Pimonrat Wanwaen, ${ }^{a}$ Sukon Phanichphant (iD ${ }^{\mathrm{b}}$ \\ and Khatcharin Wetchakun (D) ${ }^{c}$
}

DOI: $10.1039 /$ dOra90108c

rsc.li/rsc-advances

Correction for 'Influence of $\mathrm{Cu}$ doping on the visible-light-induced photocatalytic activity of InVO ${ }_{4}$ ' by Natda Wetchakun et al., RSC Adv., 2017, 7, 13911-13918, DOI: 10.1039/C6RA27138C.

The authors regret errors in Fig. 4, 7, and 9 in the previously published article. The corrections for the errors in the article are described as follows:

(1) The diffuse reflectance spectra of pure $\mathrm{InVO}_{4}$ and $1.0 \mathrm{~mol} \% \mathrm{Cu}$-doped $\mathrm{InVO}_{4}$ are shown in Fig. 4. The absorption margin of $1.0 \mathrm{~mol} \% \mathrm{Cu}$-doped $\mathrm{InVO}_{4}$ was shifted to a longer wavelength, indicating a decrease in the band gap with respect to pure $\mathrm{InVO}_{4}$. The absorption margins of the pure $\mathrm{InVO}_{4}$ and $1.0 \mathrm{~mol} \% \mathrm{Cu}$-doped $\mathrm{InVO}_{4}$ samples were $505 \mathrm{~nm}$ and $510 \mathrm{~nm}$, corresponding to band gaps of $2.51 \mathrm{eV}$ and $2.45 \mathrm{eV}$, respectively (Fig. $4 \mathrm{a}$ and b).

(2) The band edge positions of the conduction band (CB) and the valence band (VB) of $\mathrm{InVO}_{4}$ can be calculated by the following equation: $E_{\mathrm{CB}}^{0}=\chi-E^{\mathrm{C}}-0.5 E_{\mathrm{g}},{ }^{1}$ where $\chi$ is the electronegativity of the semiconductor, $E^{\mathrm{C}}$ is the energy of free electrons on the hydrogen scale of $4.5 \mathrm{eV}, E_{\mathrm{g}}$ is the band gap of $\mathrm{InVO}_{4}$, and the $\chi$ value of $\mathrm{InVO}_{4}$ is $5.74 \mathrm{eV}^{2}$ The $E_{\mathrm{g}}$ value of $\mathrm{InVO}_{4}$ evaluated from the UV-vis DRS analysis was about $2.51 \mathrm{eV}$. The valence band energy $\left(E_{\mathrm{VB}}\right)$ can be calculated by the following equation: ${ }^{3} E_{\mathrm{VB}}=E_{\mathrm{CB}}+E_{\mathrm{g}}$, where $E_{\mathrm{CB}}$ is the conduction band energy. Based on the equation above, the calculated CB and VB edge potentials of $\mathrm{InVO}_{4}$ were $-0.02 \mathrm{eV}$ and $2.49 \mathrm{eV}$, respectively. Now, we are in a position to discuss the photocatalytic mechanism of Cu-doped $\mathrm{InVO}_{4}$ for $\mathrm{MB}$ degradation (Fig. 7). In the photocatalysis process, when the absorbed photon energy ( $h v)$ equals or exceeds the band gap, the $\mathrm{Cu}$ doped $\mathrm{InVO}_{4}$ generates electron-hole $\left(\mathrm{e}^{-} / \mathrm{h}^{+}\right)$pairs. In that case, the generated electrons from the valence band can be transferred to the conduction band of $\mathrm{InVO}_{4}$. Since the CB edge potential of $\mathrm{InVO}_{4}(-0.02 \mathrm{eV})$ is higher than the standard redox potential, $E^{0}\left(\mathrm{O}_{2} / \mathrm{O}_{2}{ }^{-}\right)=-0.33 \mathrm{~V} v$ s. NHE at $\mathrm{pH} 7$, this suggests that the electrons in the $\mathrm{CB}$ of $\mathrm{InVO}_{4}$ cannot reduce $\mathrm{O}_{2}$ to the superoxide
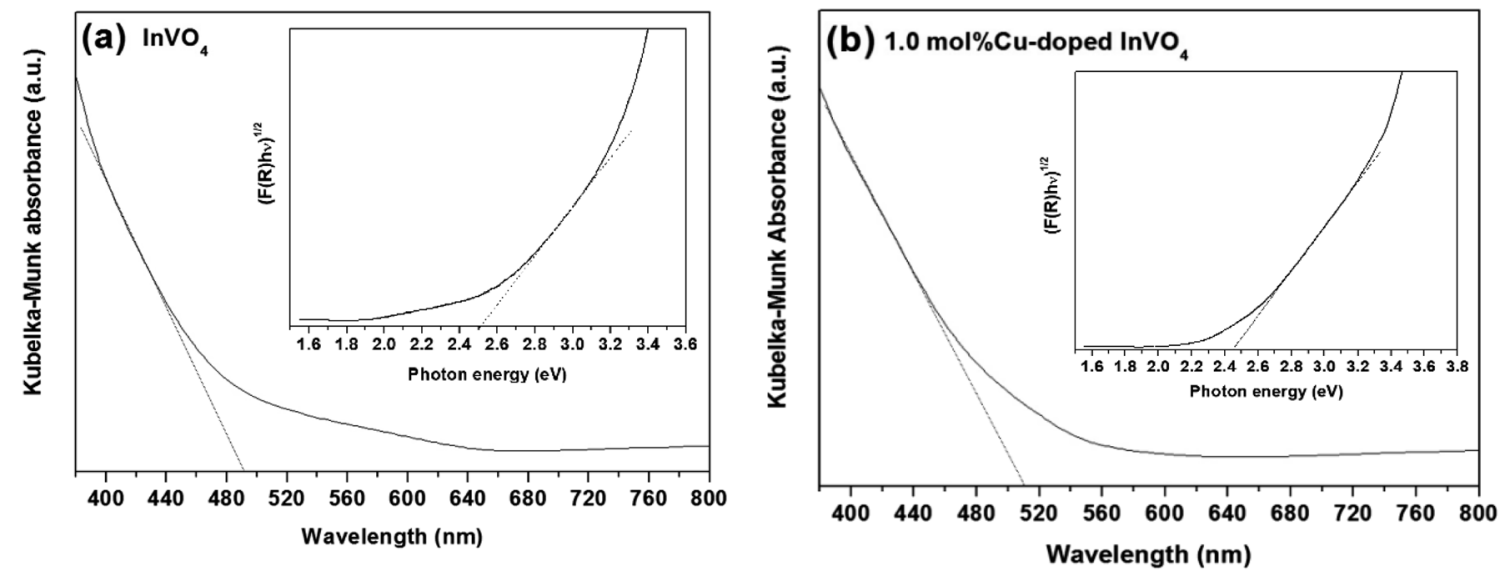

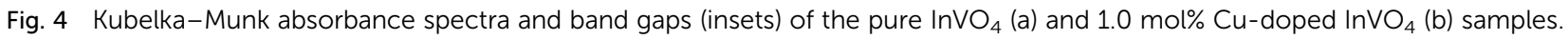

${ }^{a}$ Department of Physics and Materials Science, Faculty of Science, Chiang Mai University, Chiang Mai 50200, Thailand. E-mail: natda_we@yahoo.com ${ }^{b}$ Materials Science Research Center, Faculty of Science, Chiang Mai University, Chiang Mai 50200, Thailand

'Program of Physics, Faculty of Science, Ubon Ratchathani Rajabhat University, Ubon Ratchathani 34000, Thailand 


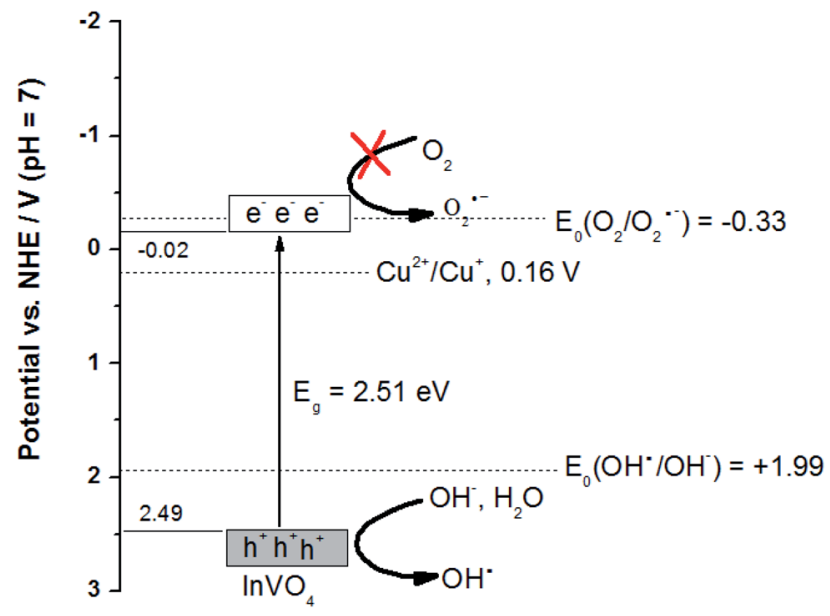

Fig. 7 Schematic of the charge migration and separation on $\mathrm{Cu}$-doped $\mathrm{InVO}_{4}$.

radical ion $\left(\mathrm{O}_{2}{ }^{-}\right)$. In addition, the $\mathrm{VB}$ of $\mathrm{InVO}_{4}(2.49 \mathrm{eV})$ is higher than the standard redox potential, $E^{0}\left(\mathrm{OH}^{-} / \mathrm{OH}^{*}\right)=1.99 \mathrm{~V} v s$. NHE at $\mathrm{pH}$ 7. This indicates that the photogenerated holes in the valence band of $\mathrm{InVO}_{4}$ can oxidize the hydroxyl ion $\left(\mathrm{OH}^{-}\right)$or water $\left(\mathrm{H}_{2} \mathrm{O}\right)$ to form the hydroxyl radical $\left(\mathrm{OH}^{*}\right)$.

(3) Due to the contradiction between the scavenging test and the proposed photocatalytic mechanism, Fig. 9 was removed from the original article.

The Royal Society of Chemistry apologises for these errors and any consequent inconvenience to authors and readers.

\section{References}

1 H. Q. Jiang, H. Endo, H. Natori, M. Nagai and K. Kobayashi, Mater. Res. Bull., 2009, 44, 700-706.

2 F. Guo, W. Shi, X. Lin, X. Yan, Y. Guo and G. Che, Sep. Purif. Technol., 2015, 141, 246-255.

3 G. Magesh, B. Viswanathan, R. P. Viswanath and T. K. Varadarajan, Indian J. Chem., 2009, 48A, 480-488. 